\title{
Multidisciplinary management of homozygous sickle cell patients: Dental treatment pathologies and needs
}

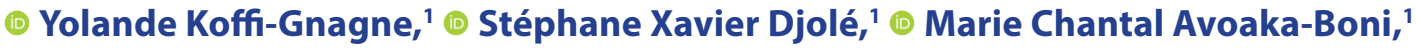

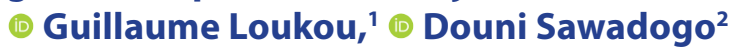

'Department of Dentistry and Endodontics, Odonto-Stomatology Faculty, Felix Houphouët Boigny University, UFHB, Abidjan, Ivory Coast
'Faculty of Pharmaceutical Sciences of Felix Houphouët Boigny University UFHB Abidjan, Abidjan, Ivory Coast

Objective: The objective of this study was to assess the oral state of patients with homozygous sickle cell disease (SSD) to identify preventive and curative care needs.

Methods: Our study was carried out in the first Clinical Hematology service in West Africa in the Yopougon University Hospital (Abidjan- Côte d'Ivoire). A retrospective analysis of SS patients' records followed by interviews and dental screenings was carried out. The data collected was processed with the use of EPI Info software version 6.01.

Results: Sixty patients were examined. Detected pathologies were chronic pulpitis (33\%), dentinal sensitivity $(23 \%)$, chronic apical periodontitis (17\%), and pulpal necrosis (10\%). Dental care needs were surgical (14\%), prosthetic (16\%), conservative (24\%) and prophylactic (46\%).

Conclusion: The importance of this work is to propose a dental management of patients with homozygous sickle cell disease.

Keywords: Dental manifestations; dental treatment; homozygous sickle cell.

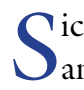
ickle cell (SS) is a hemoglobinopathy resulting in an anemia due to the distortion of red blood cells (RBS) into sickle-shaped. This condition is common with mass migration and intermingling of populations and is particularly widespread in black African and Indian populations. It is, for example, the most common genetic disease in France. The prevalence of hemoglobin $S$ is $12 \%$ in Côte d'Ivoire.

Oral complications of the sickle cell disease (SSD) have been established since the end of the last century's first clinical cases. Oral signs of SSD include oro-facial pain, mesiofaciale overgrow, malocclusions, enamel hypominer- alization and a caries-promoting factor. ${ }^{[1,2]}$ Indeed, this is due to the sickle erythrocyte that upsets the blood flow in the pulp environment. In addition to orofacial syndromes, the malocclusions were aggravated by the association of the hypoxia to the jaw osteomyelitis and the bone marrow hyperplasia. ${ }^{[3,4]}$ In the dental environment, the major form of the disease characterizes the described pathophysiology. It is the homozygous SSD, defined as a chronic hemolytic anemia interspersed with hemolytic seizures and vaso-occlusive attacks often complicated by severe bacterial infections. ${ }^{[5,6]}$ A pulpal necrosis caused by the association of hypoxia with decreased blood supply to the teeth disorder

Correspondence: Dr. Yolande Koffi-Gnagne. Felix Houphouët Boigny University Ufhbabidjan,

22 Bp 612 Abidjan 22. 612 Abidjan - Cote d'Ivoire.

Tel: +225 - 01108082 e-mail: gkyolande@gmail.com

Submitted: December 21, 2018 Accepted: January 24, 2019 
affected dental tissues. ${ }^{[2]}$ Indeed, the erythrocytes sickleshaped impedes the pulp microcirculation. Recent studies have also shown that the oral environment of children suffering from the pathology is an enabling environment of the spread of decaying disease pathogens..$^{[7,8]}$ Moreover, people's negligence regarding their oral health could lead to the handicap caused by hemoglobinopathies. All these factors combined to justify the poor oral state of patients suffering from this type of pathology. In Côte d'Ivoire, the prevalence of hemoglobin $S$ is estimated at $12 \%$, a similar prevalence is also found in other sub-Saharan countries. ${ }^{[9]}$ Although Côte d'Ivoire shelters the first clinical hematology service in West Africa, no studies dealt with the oral health of SSD patients to ensure their full management. This study was therefore carried out to assess the oral state of patients suffering from homozygous SSD to identify preventive and curative care needs.

\section{Materials and methods}

It was a two-month prospective study in the Clinical Hematology Department and at the Central Laboratory of the Reference Center. It was carried out in two phases involving a retrospective analysis of patients' records, followed by a prospective investigation combining interviews and oral examinations.

\section{Prospective survey}

Medical records of hemoglobin phenotypic patients were consulted. Information on hematology analyses has been identified. The blood count included several parameters, some of which are the subject of our study. We specifically focused on (RBC) count. Values, which were admitted as a norm are typical [4-4.5] 106/MM3 in women and [4.56] 106/MM3 in men. Finally, data related to periodicity and type of attacks (hemolytic or vaso-occlusion) were recorded.

\section{Interviews and oral examinations}

Selected patients were informed about the objectives of the study to obtain their informed consent to participate in the study. They were interviewed based on the WHO1997 form of the annual frequency of SSD crisis and the association of dental pain with the onset of these attacks. Thereafter, an operator aided by an Assistant carried out clinical examinations. Plaque and dental tartar presence was used to determine every patient's Simplified Oral Hygiene Index (SOHI). Decayed teeth $(\mathrm{D})$, missing due to extraction $(\mathrm{M})$ and filled $(\mathrm{F})$, were identified to calculate the average DMF index. Patients were then divided into two variables: ( 1 ) with cavities or (2) without cavities. Spe- cial examinations of teeth were conducted on a cavity random basis, pulp vitality test (dental cold spray, Maecolux ${ }^{\circledR}$, Luxembourg) and periodontal test (axial and transverse percussion). The standard practice of panoramic X-rays of the maxilla was done when needed with periapical X-rays (Kodak $6100^{\circledR}$; Kodak, Paris, France).

For each patient, the most severe dental pathology was selected as the only identifier assigned to the subject for statistical analysis.

\section{Statistical analysis}

The data collected was processed with EPI Info software version 6.01 . The statistical analyses were carried out by the KHI2 test and the Kruskall-Wallis non-parametric test was used to compare qualitative and quantitative variables averages. The significance threshold was set at $5 \%$ for observed differences.

\section{Results}

Sixty patients aged 12 to 40 years (average age $=20$ years) made up the study sample. Gender-related distribution was $56.7 \%$ of women for $43.3 \%$, giving a sex ratio of 0.7 . More than half of examined patients (58\%) had poor oral hygiene measured by the SOHIS (Fig. 1). The average DMF index was 3.25 , reflecting the majority of carious lesions in $65 \%$ of tested patients. Patients had $83.3 \%$ of substance loss due to carious lesions or hypomineralization, divided into pulp attacks (43\%), dentin attacks (23\%) and periapical attacks (17\%) (Fig. 2). Diagnoses of those attacks showed that chronic pulpitis was one-third of

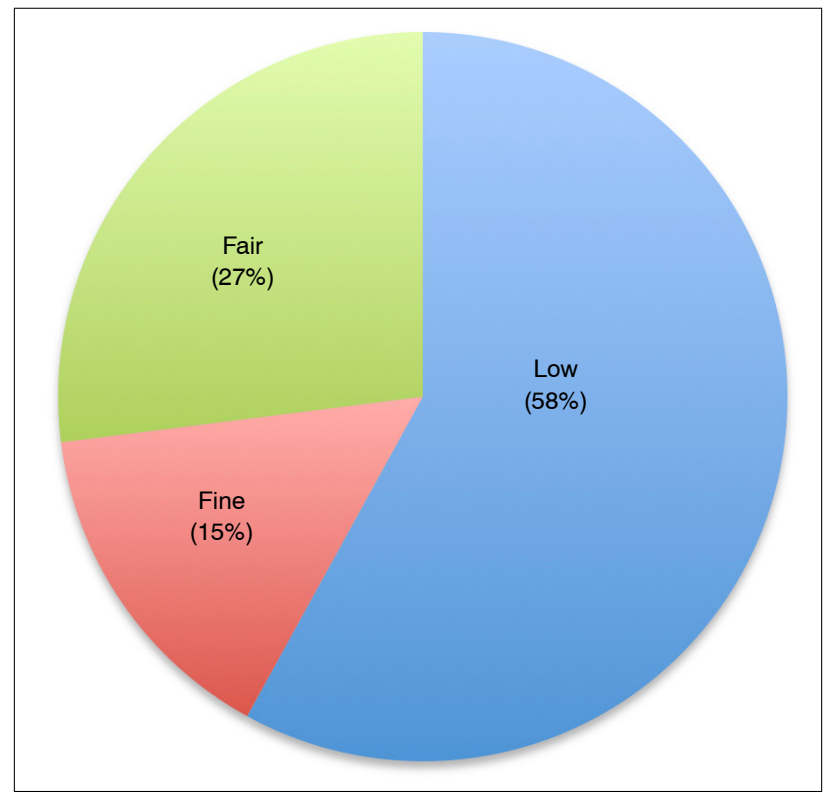

Fig. 1. Distribution of the $\mathrm{SOHI}$ in the study population. The majority of patients examined have unsatisfactory oral hygiene. 


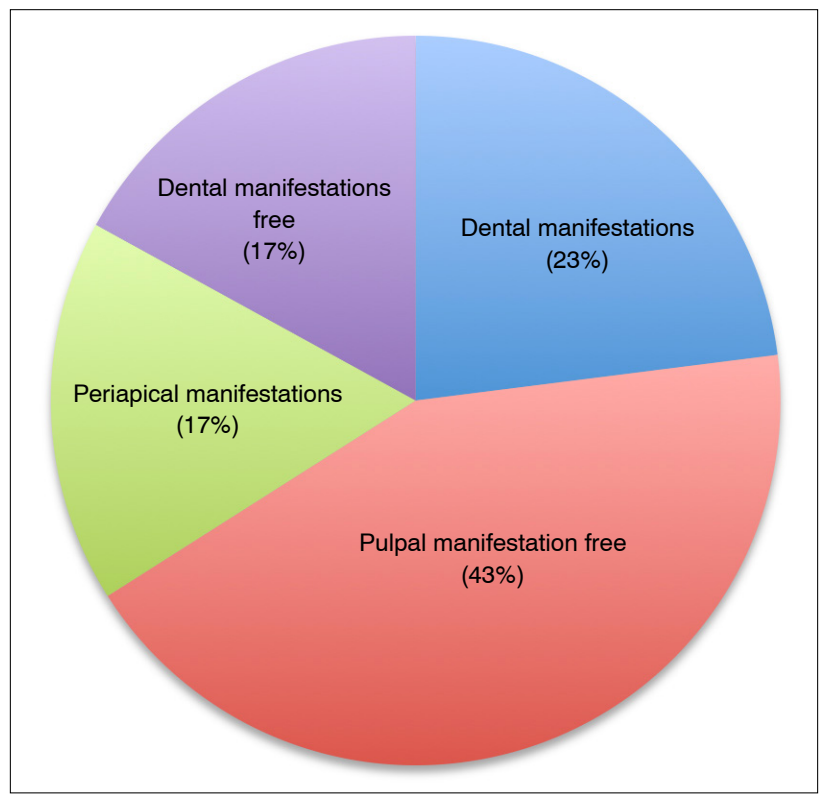

Fig. 2. Distribution of dental signs encountered in patients with sickle cell. Pulp inflammations with painful symptomatology are the most experienced manifestations of patients.

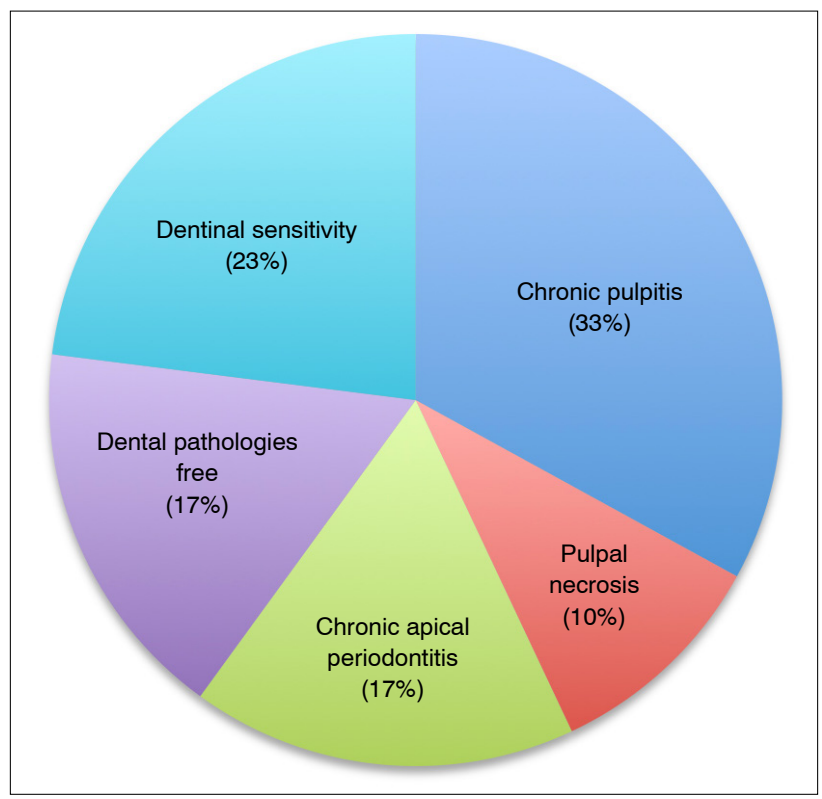

Fig. 3. Distribution of dental pathologies encountered in patients with sickle cell anemia. 1/3 of diagnosed teeth has chronic pulpitis.

identified pathologies (33\%), followed by reversible pulpitis (23\%), chronic apical periodontitis (17\%), and pulpal necrosis (10\%) (Fig. 3). $60 \%$ of teeth with healthy-looking and without loss of substance had chronic pulpitis. Some patients recall an episode of dental pain during their hemolytic or vaso-occlusive seizures. Said combination concerned $75 \%$ of patients with dental pathologies (Fig. 4) and the recurrence of these seizures was associated with a gradual disappearance of the pain (Fig. 5). Analysis of

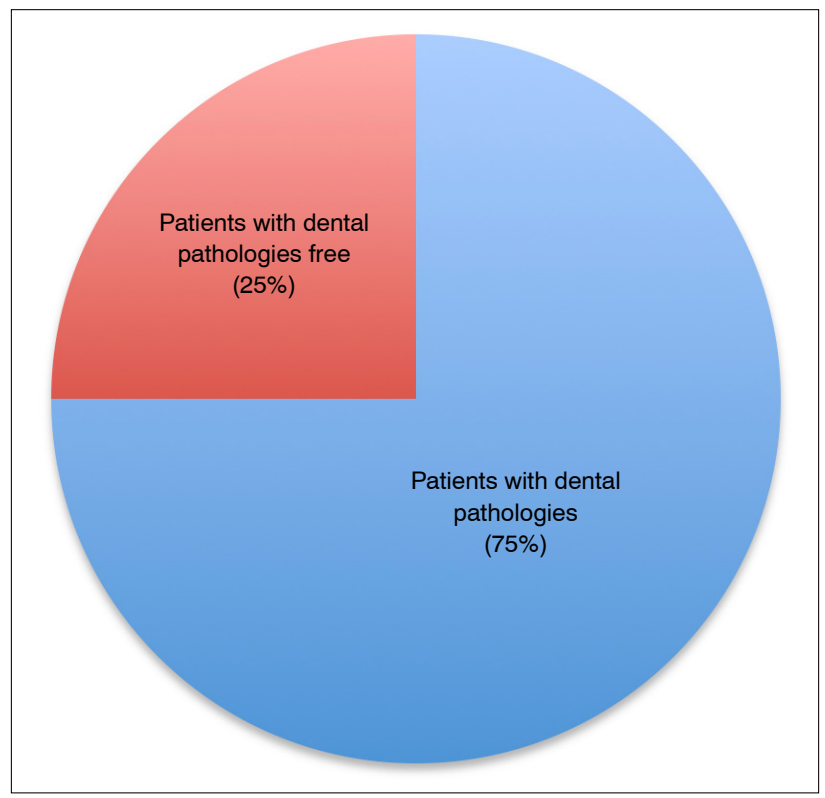

Fig. 4. Distribution of patients according to the occurrence of sickle cell attacks. $75 \%$ of patients with SSD seizures have cavities.

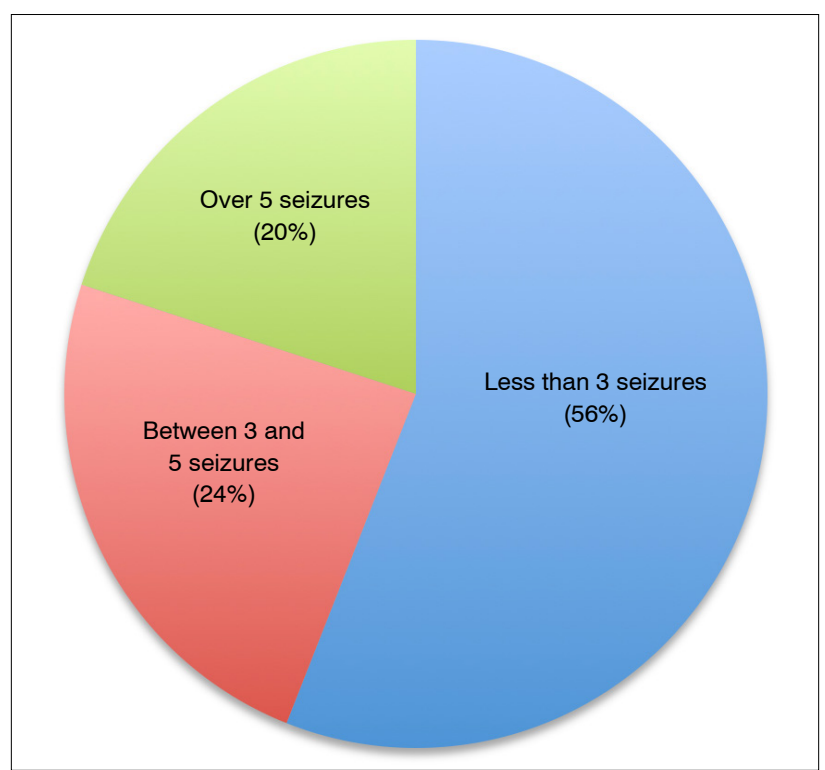

Fig. 5. Distribution of the occurrence of dental pain according to the annual frequency of SSD seizures. The more attacks are recurrent the less teeth are affected by the painful symptomatology $(p=0.001523)$.

erythrocyte parameters revealed that $92 \%$ of patients with decayed teeth had RBC deficiency (Fig. 6). These data reflect, in ascending order, care needs: surgical (14\%), prosthetics (16\%), preservatives (24\%), and caries disease prophylaxis (46\%) (Fig. 7).

\section{Discussion}

SS or SS anemia is the most common hemoglobinopathy, and predominant mainly at the geographical band between 


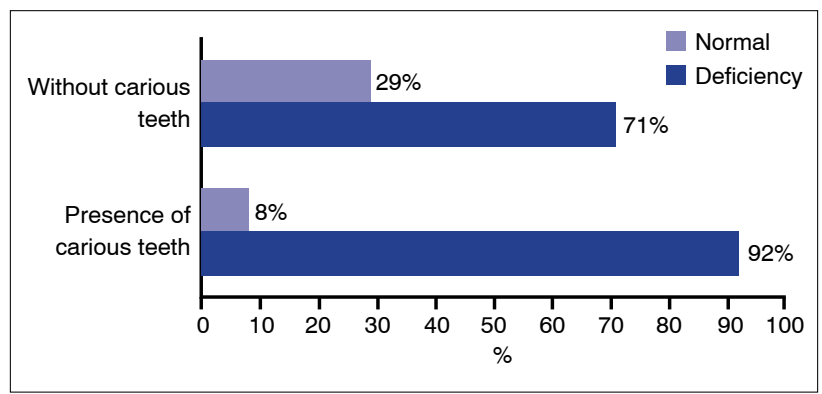

Fig. 6. Distribution of patients according to red blood cell deficiency. The erythrocyte deficiency determines the sickle disease $(p=0.0074)$.

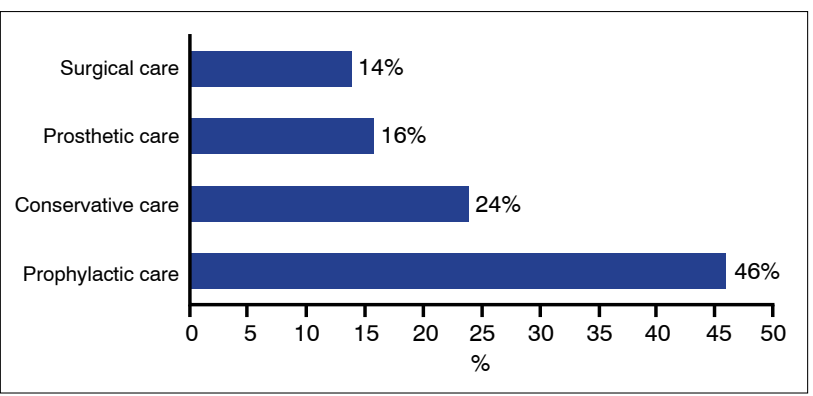

Fig. 7. Distribution of patients with sickle cell disease dental care needs. All patients examined need primary care.

the $15^{\text {th }}$ parallel north and the $20^{\text {th }}$ parallel south called "sickle belt" as defined by Lehmann. ${ }^{[5]}$ This study shows that SSD has a wide variety of disorders at the dental organ by attacks on the enamel, the dentin, the pulp and the periodontium.

\section{Oral status of patients with sickle cell disease}

As described by early works about SS dental symptoms, our study shows that the dental pulp is the most affected tissue by the disease. ${ }^{[11]}$ The Vaso-occlusive crisis characterizes the critical phase of SSD and first clinical signs are pains in the child's limbs and in the adolescent's abdomen. ${ }^{[12,13]}$ Tested patients from this study had dental pains during vasoocclusive and hemolytic attacks. The pulp vaso-occlusive crisis causes an ischemia which describes the dental pain etiology. ${ }^{[5]}$ First studies in Côte d'Ivoire had focused on the screening and medical management of the disease. ${ }^{[10]}$ This study highlights the frequency of pulp and periapical chronic pathologies. Firstly, the high prevalence of chronic pulpitis is due to the sickle cell in the dental pulp during pulp and calcifications attacks. ${ }^{[1,14,15]}$ Secondarily, the evolution towards the necrosis represents a bacterial source capable of initiating apical periodontitis. By a considerable number, reversible pulpitis related to dentin lesions is the second detected dental pathology. It was proven that the SS patient oral environment's alterations promote the initiation and hosting of amelo-dentin lesions. Indeed, children with SS have a reduction of the salivary buffering capacity $^{[7]}$ and a greater virulence of pathogen bacteria associated with carious lesions, ${ }^{[8]}$ due to an increase in production of acids which lower the $\mathrm{pH}$ of the buccal environment. In this context, the hypomineralization of hardened tissue in SS patients is an extra favorable setting for the loss of dental substance in the event of a bacterial attack.

This investigation also reveals that patients with carious lesions have a greater recurrence of SSD's seizures. This recurrence of crises is associated in the long term with the loss of the tooth vitality. Hemolysis in the dental pulp also helps to install asymptomatic irreversible pulpitis without the loss of clinically perceptible hard tissue. Observation of erythrocyte parameters revealed that patients with low $\mathrm{RBC}$ count are more prone to caries. Indeed, because these cells are blood iron vectors, current studies show that iron deficiency anemia increases the susceptibility for developing a carious disease. ${ }^{[16,17]}$

\section{Dental treatment needs}

Analysis of results showed that the high DMF index of the study population was due to the frequency of decayed teeth and missing teeth. A need for prophylactic care is, therefore, necessary for all seen patients. This concerns the detected enamel and dentin initial lesions. However, preventive care is necessary for all patients. The correlation between the recurrence of SSD attacks and the presence of necrotic teeth is proven. ${ }^{[18]}$ Our results show that major curative treatments concern endodontic therapy. Identified chronic pathologies also showed the frequency of teeth in their root state, requiring avulsions. This could justify the need for occluso-functional rehabilitation in these patients.

From an epidemiological point of view, these dental care needs are not specific to SSD patients. But it is about a population in need of special medical care, not to exacerbate or deteriorate their general health status. The orofacial sphere is not the only one affected by manifestations of SS, but once the diagnosis of the disease has been established, oral rehabilitation and the application of preventive measures should be introduced. In this sense, the RBC can be a first indicator of the introduction of the dentistry therapeutic strategy and the treatment of oral complications must be adapted to each patient's systemic state and special needs.

\section{Conclusion}

This study complements existing data on SS anemia's oral consequences. For obvious reasons, emphasis must be placed on a multidisciplinary approach in the monitoring of patients with SSD. The objective of this work is to sug- 
gest a dental management of patients with homozygous SS. It goes through the integration of a systematic oral examination from the presumption of the disease to the introduction of preventive measures adapted to each patient, and the supervision for the treatment of oral complications due to the recurrence of SS attacks.

\section{Funding}

No funding was received for this work.

Conflict of interest: None declared.

\section{References}

1. Kelleher M, Bishop K, Briggs P. Oral complications associated with sickle cell anemia: a review and case report. Oral Surg Oral Med Oral Pathol Oral Radiol Endod 1996;82:225-8.

2. Javed F, Correa FO, Nooh N, Almas K, Romanos GE, Al-Hezaimi K. Orofacial manifestations in patients with sickle cell disease. Am J Med Sci 2013;345:234-7.

3. Costa CP, Carvalho HL, Souza Sde F, Thomaz EB. Is sickle cell anemia a risk factor for severe dental malocclusion? Braz Oral Res 2015;29. pii: S1806-83242015000100219.

4. Mulimani P, Ballas SK, Abas AB, Karanth L. Treatment of dental complications in sickle cell disease. Cochrane Database Syst Rev 2016;4:CD011633.

5. Allison AC. Polymorphism and natural selection in human populations. Cold Spring Harb Symp Quant Biol 1964;29:137-49.

6. Bsoul SA, Flint DJ, Terezhalmy GT, Moore WS. Sickle cell disease. Quintessence Int 2003;34:76-7.

7. de Matos BM, Ribeiro ZE, Balducci I, Figueiredo MS, Back-Brito GN, Mota AJ, et al. Oral microbial colonization in children with sickle cell anaemia under long-term prophylaxis with penicillin. Arch Oral Biol 2014;59:1042-7.

8. Brighenti FL, Medeiros AC, Matos BM, Ribeiro ZE,
Koga-Ito CY. Evaluation of caries-associated virulence of biofilms from Candida albicans isolated from saliva of pediatric patients with sickle-cell anemia. J Appl Oral Sci 2014;22:484-9.

9. Ranque B, Menet A, Diop IB, Thiam MM, Diallo D, Diop $\mathrm{S}$, et al. Early renal damage in patients with sickle cell disease in sub-Saharan Africa: a multinational, prospective, cross-sectional study. Lancet Haematol 2014;1:e64-73.

10. Tolo-Diebkilé A, Koffi KG, Nanho DC, Sawadogo D, Kouakou B, Siransy-Bogui L, et al. Homozygous sickle cell disease in Ivory Coast adults. [Article in French]. Sante 2010;20:63-7.

11. Soni NN. Microradiographic study of dental tissues in sickle-cell anaemia. Arch Oral Biol 1966;11:561-4.

12. Page C, Gardner K, Height S, Rees DC, Hampton T, Thein SL. Nontraumatic extradural hematoma in sickle cell anemia: a rare neurologicalcomplication not to be missed. Am J Hematol 2014;89:225-7.

13. Jain S, Bakshi N, Krishnamurti L. Acute Chest Syndrome in Children with Sickle Cell Disease. Pediatr Allergy Immunol Pulmonol 2017;30:191-201.

14. Andrews CH, England MC Jr, Kemp WB. Sickle cell anemia: an etiological factor in pulpal necrosis. J Endod 1983;9:249-52.

15. Cox GM, Soni NN. Pathological effects of sickle cell anemia on the pulp. ASDC J Dent Child 1984;51:128-32.

16. Venkatesh Babu NS, Bhanushali PV. Evaluation and association of serum iron and ferritin levels in children with dentalcaries.J Indian Soc Pedod Prev Dent 2017;35:1069.

17. Souza SFC, Thomaz EBAF, Costa CPS. Healthy Dental Pulp Oxygen Saturation Rates in Subjects with Homozygous Sickle Cell Anemia: A Cross-Sectional Study Nested in a Cohort. J Endod 2017;43:1997-2000.

18. Basati MS. Sickle cell disease and pulpal necrosis: a review of the literature for the primary care dentist. Prim Dent J 2014;3:76-9. 